\title{
Compression Mass Gauge Testing in a Liquid Hydrogen Dewar
}

J.M. Jurns

NYMA Inc.,

Brook Park, Ohio

and

A.C. Rogers

Southwest Research Institute

San Antonio, Texas

July 1995

Prepared for

Lewis Research Center

Under Contracts NAS3-27186 and NAS3-25365

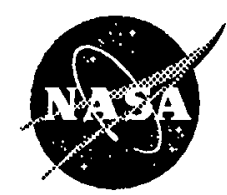

National Aeronautics and

Space Administration 


\title{
Compression Mass Gauge Testing in a Liquid Hydrogen Dewar
}

\author{
A.C. Rogers \\ Southwest Research Institute \\ San Antonio, Texas 78228 \\ and \\ J.M. Jurns \\ NYMA Inc. \\ 2001 Aerospace Parkway \\ Brook Park, OH 44142
}

\begin{abstract}
This paper describes testing that was conducted using a mass gauge in a liquid hydrogen environment. The mass gauge, referred to herein as the "compressibility gauge," is being developed as a means to accurately determine the mass of liquid contained in a tank in a low-gravity environment. The concept, described by Mord et al., ${ }^{1}$ is based on the thermodynamic principle that the pressure of gas or vapor changes when its volume changes. Previous work has been conducted by Southwest Research Institute in collaboration with NASA Lewis Research Center. This consisted of testing the concept with water and other cryogenic simulant fluids. The purpose of conducting liquid hydrogen tests is to test the concept in actual cryogenic conditions, and address hardware issues that arise in fabricating a test article for use in liquid hydrogen.
\end{abstract}

\section{NOMENCLATURE}

a tank stiffness factor

C boundary layer coefficient

$f \quad$ volume change frequency

$P \quad$ tank total pressure

DP tank pressure change with volume change

$V \quad$ gas or vapor volume

DV tank volume change

g polytropic constant, specific heat ratio of gas or vapor for adiabatic process

\section{BACKGROUND}

The ability to accurately measure quantities of cryogenic fluids in a low gravity environment is a critical requirement for future space exploration missions. In low gravity, the position of the liquid in the 
container may be markedly different than it is in a one-g gravity field environment. Instead of settling in the bottom of the container, the fluid may become a mixture of gas bubbles interspersed within the liquid, which may be located randomly throughout the container. Consequently, the familiar gauging methods used on earth are not generally applicable in space. The need to develop a gauging system that will work in low gravity is evident. Many "low-g quantity gauges" have been investigated in concept or by laboratory testing over the past 30 years. These systems have been based on the use of a variety of physical principles such as radio frequency microwaves, gas bubble resonant frequency, liquid heat capacity, optical absorbency, ultrasonics, acoustics, gamma ray densitometry, and flow meters for monitoring liquids leaving and entering the tank (mass balancing). To this point, however, they have all proved to have significant limitations in gauging accuracy, complexity, or weight. Of all the potential technologies, only compressibility gauging offers the benefits of simplicity of design, minimum intrusion into the tank, high accuracy, and functionality independent of liquid orientation.

\section{COMPRESSIBILITY GAUGE CONCEPT}

The concept of compressing the ullage gas bubble as a means of gauging liquid volume has been developed previously for ground applications at the Southwest Research Institute 3 and recently for space applications. ${ }^{4}$ The physical basis of such a gauge is the relation between gas volume $V$ and gas pressure $P$, when a small adiabatic volume change $\mathrm{D} V$ is used to produce a corresponding small change in pressure $\mathrm{D} P$ :

$$
V=-\gamma P \frac{\Delta V}{\Delta P}
$$

In principle, a compressibility gauge does not require knowledge of the way gas is distributed in the tank. In practice, however, several considerations may limit the applicability of Eq. (1) and cause a need for more elaborate gauging controls and data analyses:

(1) Liquid compressibility

(2) Tank elasticity

(3) Heat, mass, and momentum effects

(4) Thermodynamic phase change

(5) Multiple ullage bubble resonances

(6) Density stratification

(7) Noncondensible pressurant gas

(8) Liquid motion

Each of these factors can be addressed by modifications to Eq. (1), or by modifying the compressibility gauge operating procedure. A more detailed explanation of the modification for each of these factors has been covered in previous works. ${ }^{2}$ Taking into account these effects, the resulting equation for $V$ is:

$$
V=-\gamma P\left(\frac{\Delta V}{\Delta P}-\alpha\right)\left(1+\frac{C}{2 \sqrt{f}}\right)^{-1}
$$

By algebraically equating $V$ for two values of frequency $f$, the parameter $C$ can be eliminated from Eq. (2) to yield Eq. (3): 


$$
V=\frac{\gamma P\left[\left(\Delta V / \Delta P_{1}-\alpha\right) \sqrt{f_{1} f_{2}}-\left(\Delta V / \Delta P_{2}-\alpha\right)\right]}{\sqrt{f_{1} f_{2}}-1}
$$

\section{PREVIOUS TESTS}

To properly assess the viability of the compressibility gauge in a cryogenic tank in a microgravity environment, the different effects that influence its accuracy must be examined. Some of these effects have been investigated in previous tests conducted with water and a cryogenic simulant fluid (either Freon R-11, or HCFC-123).

Initial tests to validate the gauging concept were conducted by Ball Aerospace. ${ }^{1}$ These tests used water in a commercial 210 liter stainless steel process drum modified to include a compression driver and pressure sensing head. The tests confirmed the accuracy of the gauging system, showed dependence of boundary layer coefficient " $C$ " on fill level, investigated the effect of cooperative bubble resonance, and gave some insight into pressure transducer location and orientation.

Further tests conducted by Southwest Research Institute, ${ }^{3,4}$ used R-11 refrigerant as a cryogenic simulant fluid. These tests confirmed the accuracy of the gauging system with a condensible fluid. They also investigated tank total pressure effect, pulser frequency and fluid quantity effects, and unsteady heat transfer effects. They also reported progress in pressure sensing by using and evaluating a "spark plug" type of piezoelectric transducer that mounted directly to the tank wall in contact with the tank contents.

The ability of the compressibility gauge to function in microgravity was also examined by NASA LeRC. A compressibility gauge using R-11 refrigerant was flown on a Lear jet, and subjected to lowgravity trajectories. Results from these tests were inconclusive because of the noise and vibration in the Lear jet. However, these tests did reveal some interesting results that will aid in developing better pressure signal processing procedures and gauge sensing head design.

\section{LIQUID HYDROGEN TESTING}

The applicability of the compressibility gauge in cryogenic fluids requires the development of components that will operate in a cryogenic environment. Previous tests, both water and cryogenic simulant, were conducted at ambient temperatures and pressures. The tests described in this report were conducted with a compressibility gauge which operated in a liquid hydrogen dewar. The gauge was designed and built by Southwest Research Institute, ${ }^{5}$ and is shown in Fig. (1). It was tested in a liquid hydrogen dewar at the NASA LeRC Cryogenic Components Lab cell 7 research facility.

\section{Cryogenic Compressibility Gauge}

The compressibility gauge shown in Fig. (1) consisted of a $186.4 \mathrm{~W}$ (1/4 hp) non-synchronous 3-phase induction motor which was enclosed in a stainless steel canister, and coupled by means of an eccentric drive shaft to a stainless steel bellows assembly which was also attached to the canister. The rotation of the motor drive shaft was converted to a linear motion which pulsed the bellows assembly. The eccentric for the drive shaft was built such that the linear displacement of the bellows could be varied. For these tests, the stroke was set at $1.63 \mathrm{~cm}$, which resulted in a total DV of $38.1 \mathrm{~cm}^{3}$. The ratio of displacer DV to test tank volume $\mathrm{V}$ was on the order of $10^{-4}$, which is typical for compressibility gauging devices. ${ }^{1}$ The motor was an off the shelf $186.4 \mathrm{~W}$ motor which was modified by cleaning out the lubrication, and replacing bearings with greaseless bearings suitable for cryogenic service. The motor speed was controlled by using a variable frequency drive controller, and could vary the pulser frequency from a fraction of a hertz up to about $20 \mathrm{~Hz}$. 


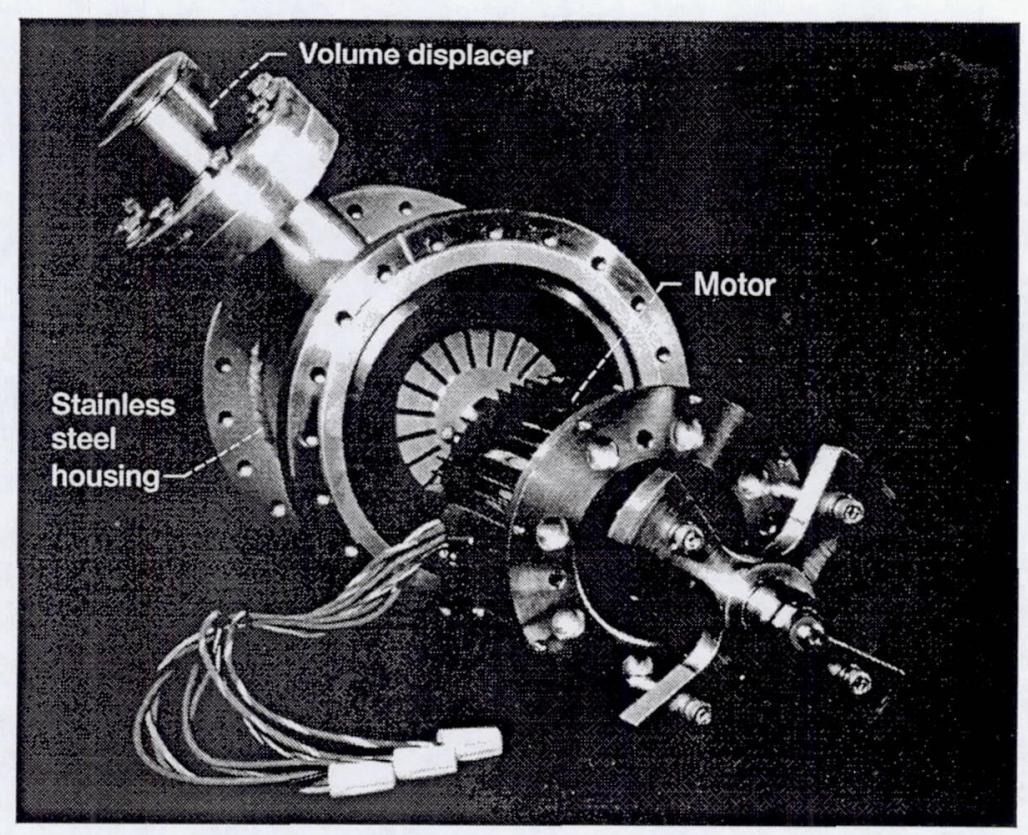

Figure 1.-Compressibility gauge-exploded view.

A piezoelectric differential pressure transducer suitable for liquid hydrogen service was attached to the cryogenic compressibility gauge to measure the differential pressure in the dewar resulting from the action of the bellows. The transducer had a range of $\pm 34.5 \mathrm{kPa}$. Motor speed was monitored by a speed sensor attached to the motor drive shaft.

\section{Liquid Hydrogen Test Facility}

The test facility where the cryogenic compressibility gauge was tested is the NASA LeRC Cryogenic Components Laboratory Cell 7. This multipurpose test facility is used for testing of cryogenic components. A schematic of the test dewar with compressibility gauge is shown in Fig. (2). A supply dewar (not shown) with an internal volume of approximately $305.8 \mathrm{~L}$ supplies liquid hydrogen to a test dewar which is $164.2 \mathrm{~L}$ internal volume. The cryogenic compressibility gauge was installed in the test dewar. Electrical power wiring was connected to the motor, instrument wiring was connected to the piezoelectric transducer, and a helium line connected to provide positive pressure to the gauge.

Both the supply and test dewars have flat flanges for lids. The lids have a short cylindrical section with an inverted dome bottom. The space between the flange and cylindrical section is evacuated and insulated with MLI to minimize heat transmission through the lid. With this arrangement, heat transfer into the test dewar due to the design of the dewar and piping penetrations is approximately $12.6 \mathrm{~W} / \mathrm{m}^{2}$.

Liquid hydrogen is transferred between the supply and test dewars through vacuum jacketed piping. The dewars can be pressurized with either helium or hydrogen gas, and can also be evacuated by means of a series of air ejectors to approximately $13.8 \mathrm{kPa}$ absolute. Maximum working pressure of the dewars is $377.1 \mathrm{kPa}$ absolute.

\section{Instrumentation and Data Acquisition}

Temperature sensors are positioned throughout the rig and on the tank walls, selected fluid lines, and components. Temperatures are measured with type $\mathrm{T}$ (copper-constantan) thermocouples and silicon diodes. Tank wall sensors are located in the annular vacuum space of the supply and test dewars, and are 


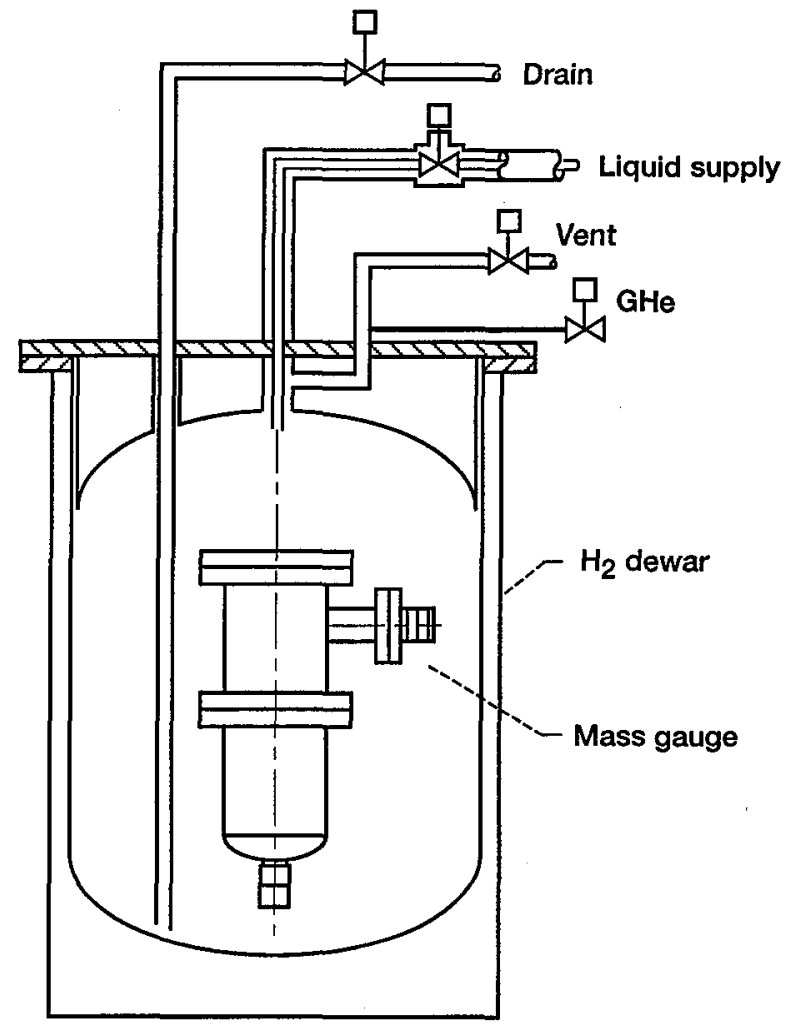

Figure 2.-Piping schematic diagram.

mounted to the inner tank wall. Within each dewar is an instrument tree with silicon diodes attached at various heights. These diodes can be used both to measure temperature of the contents to within $\pm 0.1 \mathrm{~K}$, and also as point level sensors to determine liquid level to within \pm 0.5 percent $\left( \pm 3 \mathrm{~mm}\right.$ ). ${ }^{6}$ See Fig. (3)for diode locations. A capacitance type level probe is also available to monitor liquid level. Transducers provide continuous pressure measurement throughout the system with an estimated accuracy of \pm 0.5 percent.

Data acquisition is controlled by a PC computer with software written in the $\mathrm{C}$ programming language. Nominally, 240 channels of data are taken on the test rig. Data is displayed on the CRT screen of the PC. Toggle switches, selector knobs, and continuously adjustable dials mounted on the control panel are used to control the system valves and fluid routing.

The facility data acquisition system has a nominal recording rate of one sweep every two seconds. As the compressibility gauge pulser had an nominal operating frequency of 1 to $20 \mathrm{~Hz}$, an additional data acquisition system had to be used to record the differential pressure signal generated by the gauge. This data acquisition was done by a portable notebook computer connected to a high speed data acquisition board. It was set up to record at a rate of 250 points/sec. At a maximum pulsing rate of $20 \mathrm{~Hz}$, this would provide approximately 12.5 data points per pressure pulse. An electrical voltage signal was used as a flag on both data systems to synchronize the data records.

\section{Test Procedure}

After the compressibility gauge was installed in the test dewar, the gauge was pressurized with helium. A transducer measured the internal pressure in the gauge, and pressure was typically maintained several psi above dewar pressure. The dewar was evacuated and purged with hydrogen, and then filled with liquid hydrogen to the 80 percent full level (as measured by the silicon diode tree). The gauge was run at five frequencies varying from 3 to $15 \mathrm{~Hz}$. The tank pressure, fluid temperature, gauge internal 


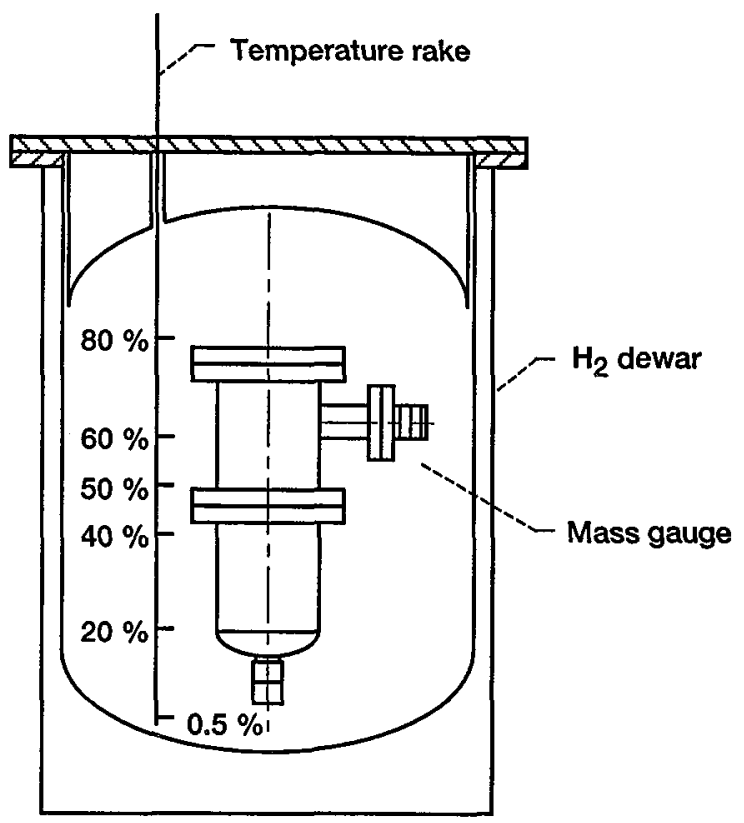

Figure 3.-Silicon diode locations.

pressure and temperature, and dewar pressure were all recorded. The tank was drained to the next level, and the test repeated. Measurements were made at the 80,60, 50, 40, 20, and 0.5 percent full tank levels.

These tests were repeated varying several parameters. For example, the dewar pressure was maintained at $103.4,137.9$, and $172.4 \mathrm{kPa}$ absolute for three different series of tests. Also, for three of the tests, the ullage volume was pressurized with helium gas instead of hydrogen gas. (The test matrix is shown in Table 1.)

Table 1. Compressibility Gauge Test Matrix

\begin{tabular}{|c|c|c|c|}
\hline Test & $\begin{array}{c}\text { Frequency, } \\
\mathrm{Hz}\end{array}$ & $\begin{array}{c}\text { Dewar press, } \\
\mathrm{kPa}\end{array}$ & Ullage gas \\
\hline 1 & 3 to 15 & 103.4 & Hydrogen \\
\hline 2 & 3 to 15 & 103.4 & Helium \\
\hline 3 & 3 to 15 & 103.4 & Hydrogen \\
\hline 4 & 3 to 15 & 103.4 & Hydrogen \\
\hline 5 & 3 to 15 & 172.4 & Hydrogen \\
\hline 6 & 3 to 15 & 172.4 & Helium \\
\hline 7 & 3 to 15 & 137.9 & Helium \\
\hline 8 & 3 to 15 & 137.9 & Hydrogen \\
\hline
\end{tabular}

\section{TEST RESULTS}

Test results were used as input to Eq. (3) which is referred to as a Dual Frequency Model. This model assumes that the Boundary Layer Coefficient $C$ is not zero, and thus requires test data at two 
different frequencies to calculate the volume. Plots are presented in Figs. 4 and 5 for gauging accuracy for $103.4 \mathrm{kPa}$ tests and for 137.9 and $172.4 \mathrm{kPa}$ tests, as functions of fill level in the tank.

\section{Ambient Pressure Tests}

These tests were conducted with the dewar at approximately $103.4 \mathrm{kPa}$ pressure. Several preliminary tests were conducted to gain experience with the system, and to become familiar with what outputs could be expected from the instrumentation. The piezoelectric differential pressure transducer originally gave spurious results. It was discovered that the transducer needed to be electrically isolated from the body of the gauge to function correctly. After the transducer was electrically isolated, it functioned properly. The tests discussed here are four series of tests which were run after test conditions were fairly well understood and controlled. Figure 4 shows gauging accuracy as a function of vapor volume in the dewar. The gauging error was typically within \pm 5 percent of actual level as determined by the point level sensors.

The gauge functioned well in all tests. The pulser frequency was varied from 3 to $15 \mathrm{~Hz}$. At each setting, the pulser frequency remained constant (that is, no apparent fluctuations in frequency). During one test, the gauge internal pressure was intentionally increased to determine the effect of differential pressure between the gauge and the dewar. At a differential pressure of $34.5 \mathrm{kPa}$, the pulser did exhibit fluctuations in frequency. This was expected, as the motor for the gauge was designed to push only against the minimum pressure induced by the pulser. ${ }^{5}$

A small amount of helium has was introduced into the ullage during test 2 (also tests 6 and 7 of higher pressure tests). This was done to try to suppress vaporization by raising liquid pressure above the thermodynamic equilibrium pressure at the liquid temperature.

\section{Higher Pressure Tests}

These tests were similar to the ambient pressure tests, except that the dewar pressure was increased to either 137.9 or $172.4 \mathrm{kPa}$ absolute, depending on the test. Figure 5 shows the results of these tests. The pressure inside the gauge was maintained at approximately the same as the dewar pressure to minimize the additional load on the motor. Results were similar to those obtained in the ambient pressure tests. For the lowest gas volumes, however, there appeared to be a negative bias to the error.

\section{Possible Sources of Error}

Heat flux.-The test dewar, although vacuum jacketed, had a parasitic heat leak into the system of about $12.6 \mathrm{~W} / \mathrm{m}^{2}$. This heat leak caused the pressure in the dewar to rise immediately upon sealing the dewar and the operating the gauge. So, although the pressure in the dewar was nominally $103.4 \mathrm{kPa}$, it

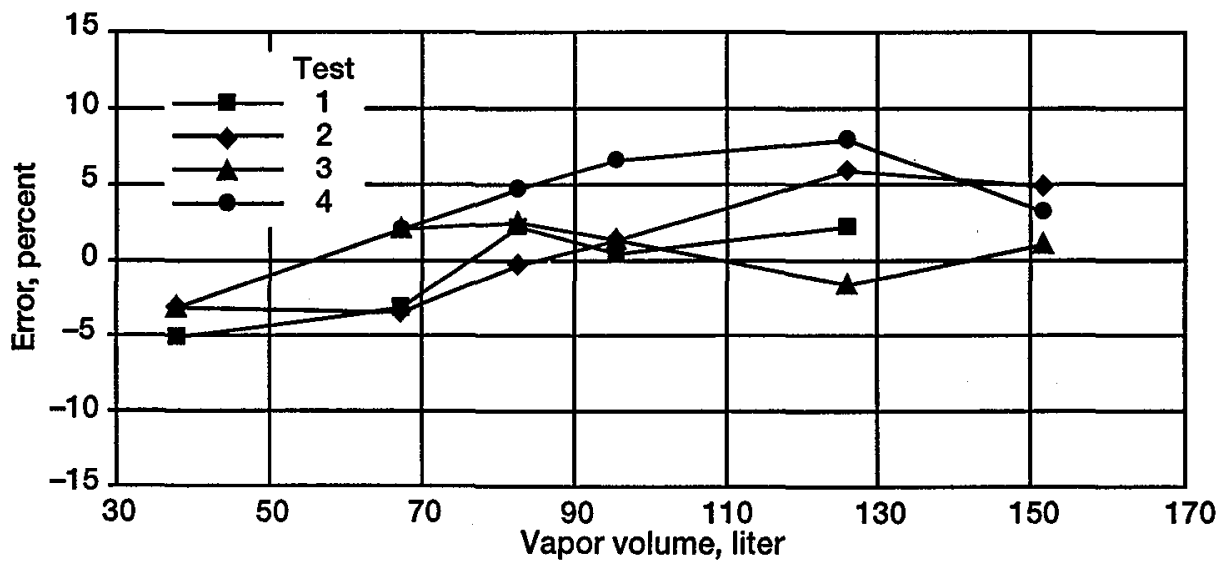

Figure 4.-Gauge error, $\mathrm{LH}_{2}$ test, $103.4 \mathrm{KPa}$ test pressure. 


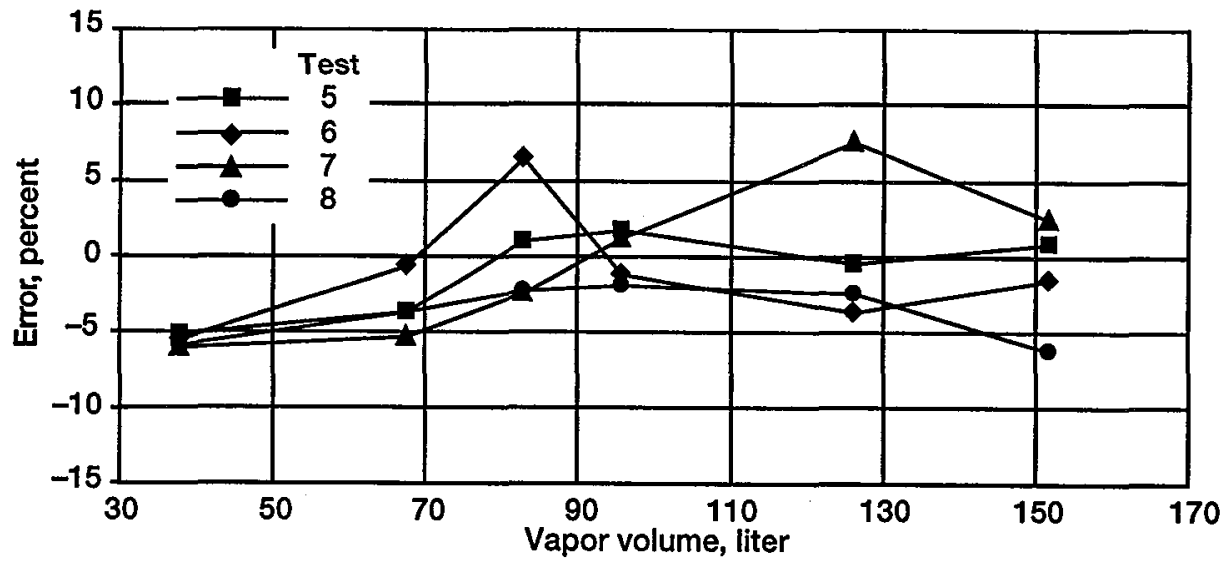

Figure 5.-Gauge error, $\mathrm{LH}_{2}$ test, 137.9 and $172.4 \mathrm{KPa}$ test pressure.

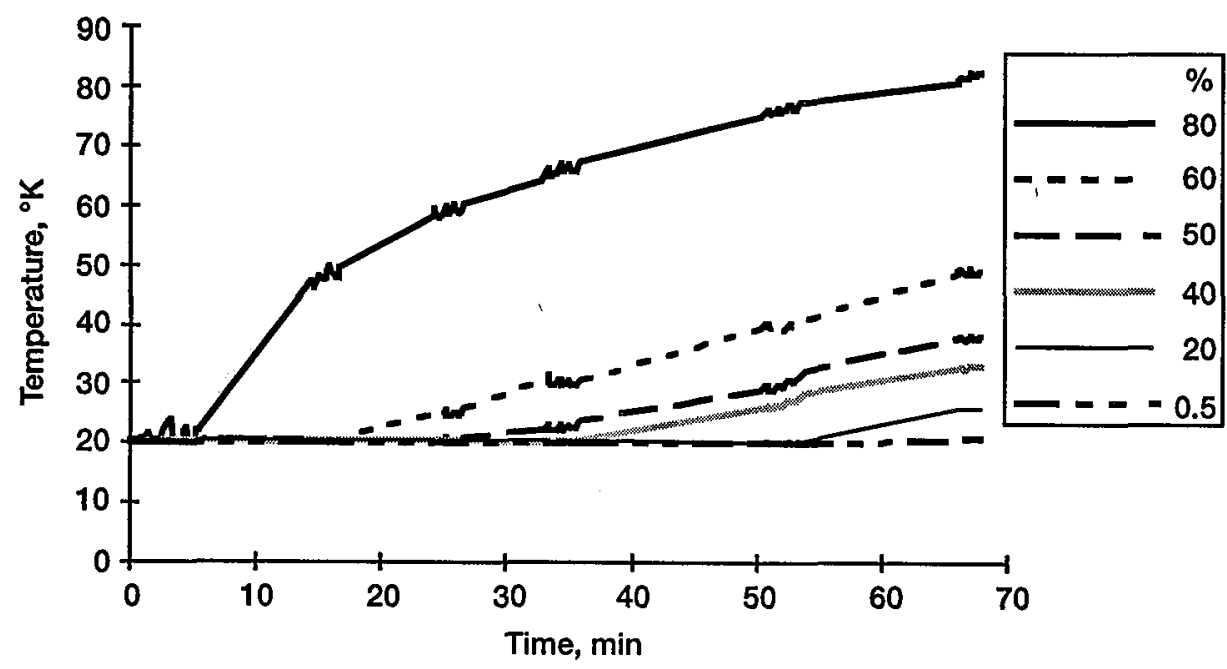

Figure 6.-Test dewar vapor temperature profile, showing stratification.

actually rose while the gauge was operating. The gauge only operated for several seconds at a time, but even for that short time, conditions were not actually steady state. As a reference for comparison, a typical space based storage tank has a heat leak of approximately $0.31 \mathrm{~W} / \mathrm{m}^{2}$, which is 40 times less than the test bed used here. The adverse effects of unsteady heat transfer are consistent with poor results reported in earlier simulated cryogen tests. ${ }^{2}$

Vapor stratification. - The heat leaked into the test dewar mostly through its lid. This resulted in significant stratification of the vapor temperature in the ullage. Refer to Fig. 6. Temperatures typically ranged from $22 \mathrm{~K}$ at the liquid vapor interface to $78 \mathrm{~K}$ at the top of the vapor ullage. The algorithm used to calculate vapor volume assumes a constant specific heat ratio. A specific heat ratio for the averaged ullage vapor temperature and composition was used in calculations.

\section{CONCLUSIONS}

Based on the results of this test program, it has been shown that a compressibility gauge can be successfully built and operated in a cryogenic liquid hydrogen environment. The gauge built for this test was a breadboard unit. That is, the purpose of building this gauge was to verify the function of each of the critical components, not to optimize the overall design. Specifically, the following was shown: 
(1) An off the shelf $186.4 \mathrm{~W}$ nonsynchronous 3-phase induction motor which has been modified for hydrogen service by cleaning out the hydrocarbon based lubrication and replacing the factory bearings with greaseless bearings suitable for cryogenic service functions successfully at liquid hydrogen temperatures. This motor provides sufficient torque to operate the gauge bellows without any significant variation in the motor speed.

(2) The piezoelectric differential transducer designed specifically for liquid hydrogen service functioned properly once it was electrically isolated from the compressibility gauge.

(3) The entire compressibility gauge could be successfully immersed in liquid hydrogen, and still function properly. The gauge with the integrated motor provides minimum design restriction. That is, it could be placed anywhere in the test dewar. The thermal impact to the dewar is minimum. A few instrument wires, the motor power wires, and a small ( $3.2 \mathrm{~mm}$ diameter tube) pressurization line were the only items protruding through the dewar. In future designs, the pressurization line may also be eliminated.

(4) The use of helium in the ullage did not improve accuracy for these tests. Calculation of vapor volume requires knowledge of the specific heat ratio $\mathrm{g}$, and our inability to accurately meter the amount of helium used was a likely source of error in determining $g$ and thus vapor volume.

(5) The compressibility gauge produced results that were typically within \pm 5 percent of actual volume. This was not as good as results from previous tests. ${ }^{2,3}$ However, this could be attributed to heat flux and vapor stratification previously mentioned. Further tests in a dewar with a lower heat leak would be desirable.

\section{REFERENCES}

1. A.J. Mord, H.A. Snyder, K.A. Kilpatrick, L.A. Hermanson, R.A. Hopkins, and D.A. Vangundy, "Fluid Quantity Gaging," Ball Aerospace Systems Report DRD MA183T, Contract NAS9-17616, 1988.

2. A.C. Rogers, F.T. Dodge, and K.A. Behring II, "Feasibility Development of a Cryo Fluid Gauging System for Space Vehicle Applications," Southwest Research Institute Report AIAA 93-1801, presented at AIAA 29th Joint Propulsion Conference June 28-30, 1993.

3. A.C. Rogers, F.T. Dodge, and K.A. Behring II, "Feasibility Development of a Cryo Gauging System for Space Vehicle Applications," Southwest Research Institute Final Report, SwRI Project No. 049664, April, 1993.

4. R. Monti, University of Naples, Italy, W. Berry, ESTEC, The Netherlands, "Liquid Gauging in Space: The G-22 Experiment", ESA Journal 1994, Vol 18.

5. A.C. Rogers, "Design Review-Cryo Hydrogen Quantity Gauge Test Hardware Design and Fabrication," Southwest Research Institute Project 04-2453-330, NASA Contract NAS3-25365, May 25, 1993.

6. Paula J. Dempsey and Richard H. Fabik, "Using Silicon Diodes for Detecting the Liquid-Vapor Interface in Hydrogen," NASA TM-105541, presented at ISA 38th International Instrumentation Symposium, April 26-30, 1992. 
Public reporting burden for this collection of information is estimated to average 1 hour per response, including the lime for reviewing instructions, searching existing data sources, gathering and maintaining the dala needed, and completing and revlowing the collectlon of intormation. Send comments regarding this burden estimale or any other aspect of this Davis Highway, Sulte 1204, Arlington, VA 22202-4302, and to the Office of Managernent and Budget, Paperwork Reduction Project (0704-0188), Washington, DC 20503.

\begin{tabular}{|l|c|c|}
\hline 1. AGENCY USE ONLY (Leave blank) & $\begin{array}{c}\text { 2. REPORT DATE } \\
\text { July } 1995\end{array}$ & $\begin{array}{r}\text { 3. REPOAT TYPE AND DATES COVEAED } \\
\text { Final Contractor Report }\end{array}$ \\
\hline
\end{tabular}

\section{IILE AND SUBTITLE}

Compression Mass Gauge Testing in a Liquid Hydrogen Dewar

6. AUTHOR(S)

J.M. Jums and A.C. Rogers

\section{PERFORMING ORGANIZATION NAME(S) AND ADDRESS(ES)}

NYMA Inc.

Lewis Research Center

Cleveland, Ohio 44135

and

Southwest Research Institute

San Antonio, Texas 78228

9. SPONSORING/MONITORING AGENCY NAME(S) AND ADDRESS(ES)

National Aeronautics and Space Administration

Lewis Research Center

Cleveland, Ohio 44135-3191
WU-198366

C-NAS3-27186

C-NAS3-25365
5. FUNDING NUMBEAS

8. PERFORMING ORGANIZATION REPORT NUMBER

E-9781

10. SPONSORING/MONITORING AGENCY REPORT NUMBER

NASA CR-198366

11. SUPPLEMENTARY NOTES

Prepared for the 1995 Cryogenic Engineering Conference sponsored by Centennial Conferences, Columbus, Ohio, July 17-21, 1995. J.M. Jurns, NYMA Inc., 2001 Aerospace Parkway, Brook Park, Ohio 44142 (work funded by NASA Contract NAS3-27186); and A.C. Rogers, Southwest Research Institute, San Antonio, Texas 78228 (work funded by NASA Contract NAS3-25365). Responsible person, Mark Manthey, Space Propulsion and Technology Division, organization code 5340, (216) 433-2750.

12a. DISTRIBUTIONAVAILABILITY STATEMENT

Unclassified - Unlimited

Subject Category 35

This publication is available from the NASA Center for Aerospace Information, (301) 621-0390.

13. ABSTRACT (Maximum 200 words)

This paper describes testing that was conducted using a mass gauge in a liquid hydrogen environment. The mass gauge, referred to herein as the "compressibility gauge", is being developed as a means to accurately determine the mass of liquid contained in a tank in a low-gravity environment. The concept is based on the thermodynamic principle that the pressure of gas or vapor changes when its volume changes. Previous work has been conducted by Southwest Research Institute in collaboration with NASA Lewis Research Center. This consisted of testing the concept with water and other cryogenic simulant fluids. The purpose of conducting liquid hydrogen tests is to test the concept in actual cryogenic conditions, and address hardware issues that arise in fabricating a test article for use in liquid hydrogen.

\begin{tabular}{|l|l|l|}
\hline $\begin{array}{c}\text { 14. SUBJECT TERMS } \\
\text { Cryogenic; Hydrogen; Mass gauging; Microgravity }\end{array}$ \\
\begin{tabular}{c|c|c|} 
17. SECURTY CLASSIFICATION \\
OF REPORT \\
Unclassified
\end{tabular} & $\begin{array}{c}\text { 18. SECURITY CLASSIFICATION } \\
\text { OF THIS PAGE } \\
\text { Unclassified }\end{array}$ & $\begin{array}{c}\text { 19. SECURITY CLASSIFICATION } \\
\text { OF ABSTRACT } \\
\text { Unclassified }\end{array}$ \\
\hline
\end{tabular}


National Aeronautics and

Space Administration

Lewis Research Center

21000 Brookpark Rd.

Cleveland, $\mathrm{OH}$ 44135-3191

Ofilolal Business

Penally for Pilvato Uso $\$ 300$

POSTMASTER: If Undellverable - Do Not Roturn 